\title{
The processing of humour by individuals suffering from schizophrenia
}

\section{Eszter Varga}

Department of Psychiatry and Psychotherapy, Medical Faculty, University of Pécs, Hungary varga.eszter@pte.hu

\section{Róbert Herold}

Department of Psychiatry and Psychotherapy, Medical Faculty, University of Pécs, Hungary herold.robert@pte.hu

\section{Zsuzsanna Schnell}

Department of Linguistics and Institute of Psychology, University of Pécs, Hungary schnell.zsuzsanna@gmail.com

\section{Réka Horvath}

Department of Neurology, Medical Faculty, University of Pécs, Hungary

horvath.reka@pte.hu

\section{Mária Simon}

Department of Psychiatry and Psychotherapy, Medical Faculty, University of Pécs, Hungary simon.maria@pte.hu

\section{András Hajnal}

Department of Psychiatry and Psychotherapy, Medical Faculty, University of Pécs, Hungary hajnal.andras@pte.hu

\section{Tamás Tényi}

Department of Psychiatry and Psychotherapy, Medical Faculty, University of Pécs, Hungary tenyi.tamas@pte.hu 
Abstract

Humour is an important component of social cognition. The last few years of cognitive research of schizophrenia provided a considerable amount of empirical evidence about social cognitive impairments in this serious neurodevelopmental disorder. The aim of this study is to investigate verbal humour comprehension and its cognitive background in a group of schizophrenic patients with normal intelligence. Results showed that patients were practically unable to understand verbal jokes, Gricean implicatures, and second-order Theory of Mind (ToM) tasks, when compared with healthy subjects. As the statistical analysis shows, verbal joke comprehension of patients living with schizophrenia significantly correlated with the comprehension of the linguistic incongruity of the Gricean implicatures and with verbal intelligence. On the other hand, smooth handling of verbal jokes did not significantly depend on the comprehension of second-order ToM and did not correlate with the comprehension of the intended meaning of the speaker's utterance in the Gricean implicatures' tasks.

Keywords: schizophrenia, humour, Gricean implicatures, IQ, Theory of Mind.

\section{Introduction}

Schizophrenia is a long-term, and one of the most deteriorating mental disorders characterised by several cognitive impairments. Among these, social cognitive impairment is probably one of the most important, which has been widely detected in schizophrenia (Pinkham et al. 2014). The term social cognition refers to the ability of processing information within a social context, of understanding and interpreting the self, others, and the self in relation to others within the social environment. It refers to the ability to perceive, understand, and respond to the intentions, behaviours, and dispositions of others (Brothers 1990). It has been pointed out that social cognition is strongly linked to functional outcome in schizophrenia and it is also a viable treatment target (Pinkham et al. 2014).

Theory of Mind (ToM) is an important core component of social cognition. ToM (often referred to as the 'mentalizing' capacity) is defined as the ability to attribute mental states (such as beliefs, knowledge, intentions) to the self and others (Dennett 1989; Frith \& Frith 1999; Woodruff \& Premack 1978). There is now substantial evidence for ToM deficit in schizophrenia (Bora et al. 2009). While ToM deficit is most pronounced during relapses, inadequate higherorder ToM capacities, such as irony (Herold et al. 2002; Varga et al. 2013), are apparent during the remission phase as well (Drury et al. 1998; Inoue et al. 2006; Bora et al. 2008).

Recently, a number of studies have focused on the pragmatic competence of schizophrenic patients in several dimensions of non-literal language processing, such as metaphor (Langdon et al. 2002a; Langdon et al. 2002b; Brüne \& Bodenstein 2005; Mo et al. 2008; Gavilán \& GarcíaAlbea 2011; Champagne-Lavau \& Stip 2010; Varga et al. 2014), irony (Langdon et al. 2002a; Langdon et al. 2002b; Herold et al 2002; Mo et al 2008; Gavilán \& García-Albea 2011; Colle et al. 2013; Varga et al. 2013; Varga et al. 2014), conversational implicatures (Corcoran \& Frith 1996; Abu-Akel 1999; Tényi et al. 2002; Mazza et al. 2008; Colle et al. 2013; Varga et al. 2014) and humour (Corcoran et al. 1997; Polimeni \& Reiss 2006; Tsoi et al. 2008; Marjoram et al. 2005; Polimeni et al. 2010; Ivanova et al. 2014). The conversational implicatures are deliberate violations of the Gricean maxims (Grice 1968; Grice 1975), which are widely used in normal, 
everyday verbal interactions in order to point at a hidden, implicitly coded opinion by the speaker (for examples see the Appendix section). In an implicature, what the speaker says is distinct from what the speaker thereby means. Implicatures appear in four basic types according to the four categories of the violated maxims: quantity implicatures, quality implicatures, relation implicatures, and manner implicatures. The proper understanding of such implicatures requires the recognition of the maxim that was flouted, and also the grasping of the reason why it was flouted (such as recognising the speaker's thoughts and intentions, i.e. mental state, in a given situation).

Since non-literal and indirect utterances are widely used in everyday verbal communication, such deficits in the smooth handling of discourse phenomena can lead to social isolation (Champagne-Lavau \& Stip 2010). According to Sperber and Wilson (Sperber \& Wilson 1986; Sperber 2000), it is widely accepted that successful communication depends on the successful inference of beliefs and intentions of the speaker in conversation, and they also highlight the role of ToM ability in understanding utterances that involve non-literal meaning.

Furthermore, schizophrenia is characterised by general neurocognitive impairments, and it is still an open question how impaired social cognition, ToM abilities, or non-literal language comprehension are influenced by general neurocognitive disturbances. In our earlier study (Varga et al. 2014), we were curious if schizophrenic patients with relatively high IQ would perform well in tasks containing non-literal language comprehension. Overall, we found impairments in the comprehension of non-literal language in schizophrenia such as in the comprehension of unconventional metaphors and the Gricean conversational implicatures, both in the linguistic realm and in the ToM questions. In the linguistic part of the task patients were asked to recognise the linguistic incongruities of the utterance by answering the following questions: "Is this a strange utterance? Why is it strange to say something like this?" In the latter, mentalization targeting task subjects were asked if they understood the intended meaning of the speaker's utterance ("What did the speaker really mean by the utterance?"). On the other hand there was no deficit detected in the comprehension of conventional metaphors and irony. However, while schizophrenic patients with higher IQ (IQ>106) did not differ significantly from the control group in the comprehension of conventional metaphors (e.g. kick the bucket), unconventional metaphors (e.g. John is a ship without a captain), and irony (e.g. What a good friend you are!), significant differences remained in both the linguistic and the ToM questions of the conversational implicatures tasks. Furthermore, the lower IQ schizophrenia subgroup (IQ $\leq 106)$ showed significant impairment in all of the non-literal language tasks except in the comprehension of conventional metaphors. According to these findings, we believe that schizophrenic patients can compensate their impaired pragmatic skills at least to some extent with their good neurocognitive functions and intact semantic processing in order to understand metaphors and irony. Besides, in the case of more demanding dimensions of non-literal language comprehension, such as conversational implicatures, good neurocognitive functions do not suffice to compensate their defected capacities and the existing pragmatic deficit remains.

From a cognitive linguistic point of view, humour is seen as a form of non-literal meaning construction, thus, its understanding requires pragmatic competence, such as making inferences about the speaker's utterance. To successfully arrive at the intended, non-literal meaning of the humorous utterances we rely on our social cognitive abilities, such as changing perspectives, and we also set up different hypotheses about other people's minds. In harmony with this, Schnell (2012) and Schnell \& Varga (2012) found significant associations between humour comprehension and ToM functions in preschool children. 
From the classical point of view humour comprehension requires the detection and the deciphering of something unexpected, incongruent (Martin 2007). Suls (2007) in his Incongruity-Resolution Theory of humour claims that to understand humour we need to fulfil two steps: the first one is to detect incongruity and the second one is the resolution of the detected incongruity. The processing of these two steps makes humour comprehension a problem-solving task. Giora (2002) argued that in humour comprehension relevance serves as the most important guideline, where among competing relevant meanings the optimally relevant one is the intended meaning of the utterance. The resolution of the incongruity is achieved by the recognition and deciphering of the intended meaning, resulting in laughter, as well known from punch lines. Nemesi (2009) argued that it may be amusing when the hearer is unable to infer an obvious thought, or when the speaker contradicts his or her own implicature, since implicatures are resolved through inferences which are drawn from the conventional meaning of the utterance, through the violation of one or more maxims, and are based on the detection of the relevant cues of the context. Veatch (1998) points out that humour contains a set of two or more incongruent elements with one of these violating an established social norm (Polimeni et al. 2010).

We believe that humour is a very complex phenomenon, and thus, the ability to perceive humour requires the activation of different higher-order cognitive strategies:

- good social cognitive abilities are essential to decipher humour, because it requires social and cultural background knowledge, and social experience, since in humour, the social and cultural constructions often serve as the backbone of incongruity (Schnell \& Varga 2012);

- when interpreting a humorous utterance we rely on our skills to change perspectives inferring the other's intentions, and thus the intended meaning of the utterance; that is, we build on our theory of mind abilities to interpret the non-literal meaning at hand;

- good intellectual functions are required to understand humour, which means good neurocognitive abilities in general;

- it requires good abstract and deductive reasoning;

- and thus the comprehension of non-literal language and linguistic/non-linguistic incongruities.

Humour comprehension in schizophrenia has been previously investigated in several studies, and most of these drew the conclusion that patients experienced difficulty in understanding humorous intentions (Corcoran et al. 1997; Witztun et al. 1999; Marjoram et al. 2005; Polimeni \& Reiss 2006; Tsoi et al. 2008; Polimeni et al. 2010; Ivanova et al. 2014) from both cognitive ("getting the joke") and affective perspectives ("enjoying the joke") (Suls 2007; Gardner et al. 1975).

Our present study aims to map the cognitive underpinnings that are responsible for the complex and flexible handling of humour by examining schizophrenic patients. Since schizophrenia has been described as the "sense of humour disorder", we believe that the better understanding of the cognitive background of humour comprehension may also shed light on the complex nature of cognitive impairments in schizophrenia.

As said, good neurocognitive abilities, such as memory, attention, executive functions, etc., are essential in perceiving and understanding humour. These abilities reflect intellectual functions in general. Schizophrenia, in turn, is characterised by general neurocognitive impairment. However, Polimeni \& Reiss (2006) and Polimeni et al. (2010) found that humour 
deficits in schizophrenia are not trivial, and there are also several significant associations between different neurocognitive subcomponents and outcome in humour perception.

Therefore, the purpose of this study was to examine verbal humour perception in a group of schizophrenic patients with good intellectual functions in order to exclude an effect of general cognitive impairment on humour comprehension, and in order to identify the influence of good general neurocognitive skills on humour understanding in schizophrenia. As schizophrenia is a heterogeneous disorder, only patients with paranoid type of schizophrenia were recruited to increase the homogeneity of the experimental group. Another purpose of our study was to detect potential associations between ToM functions and humour comprehension in order to prove the necessity of intact ToM capacities in understanding humorous utterances.

We also administered Gricean implicatures tasks (see Appendix) so as to better understand the cognitive mechanism of the detection of the incongruities in verbal jokes. Based on our previous study (Varga et al. 2014), we examined both the subject's ability to 1) recognise and understand the linguistic incongruities, and 2) to understand the intended meaning of the speaker's utterance in the implicatures.

According to findings in the relevant literature (Corcoran et al. 1997; Witztun et al. 1999; Marjoram et al. 2005; Polimeni \& Reiss 2006; Tsoi et al. 2008; Polimeni et al. 2010; Ivanova et al. 2014), we hypothesise that patients with schizophrenia perform worse in the humour tasks than control subjects, and heavily rely on their good neurocognitive skills when performing in humour comprehension tasks. Our study taps into this line of research, and we also hypothesise that humour comprehension would be significantly associated with IQ, ToM functions, and with the success of the detection and comprehension of the incongruities in the Gricean implicatures.

\section{Material and methods}

\subsection{Participants}

The present investigation comprises the same participants as in the experimental study of the same authors, formerly published as (Varga et al. 2014).

A total of 19 (ten male and nine female) Hungarian-speaking patients with paranoid type of schizophrenia fulfilling the diagnostic criteria of DSM-IV were recruited from the psychosis unit of the Department of Psychiatry and Psychotherapy, University of Pécs. The psychopathology was assessed using Positive and Negative Syndrome Scale (PANSS) (Kay \& Opler 1987). A trained psychiatrist, blinded with respect to the testing results, rated the patients. Subjects were rated using the Schedule for Affective and Schizophrenic Disorders - Lifetime Version to confirm their diagnoses (Endicott \& Spitzer 1978). All of the patients were Hungarian native speakers. Patients with history of substance abuse, neurological disorder, history of head injury, physical disability (visual or auditory), mental retardation or with schizophrenia unrelated cognitive deficits were excluded. All of the recruited patients were clinically stable and have had no significant improvement or worsening of symptoms for at least one month prior to the assessment. Frequency and severity of the symptoms were evaluated by two senior psychiatrists (Herold R., Tényi T.) by using PANSS. Eight of the patients were on maintenance antipsychotic monotherapy (amisulpiride $n=1$, clozapine $n=1$, olanzapine $n=2$, quetiapine $n=2$, risperidone $\mathrm{n}=1$, paliperidone $\mathrm{n}=1$ ), and eleven were on antipsychotic combination (flupentixol+clozapine $\mathrm{n}=2$, clozapine+aripiprazole $\mathrm{n}=1$, olanzapine+flupentixol $\mathrm{n}=1$, quetiapine+aripiprazole $\mathrm{n}=1$, olanzapine+paliperidone $\mathrm{n}=1$, flupentixol+quetiapine $\mathrm{n}=1$, risperidone+olanzapine $\mathrm{n}=1$, 
haloperidol+risperidone $n=1$, clozapine+risperidone $n=1$, and flupentixol+aripiprazole $n=1$ ) (the average chlorpromazine equivalent was $605 \mathrm{mg} /$ day \pm 383 ). There was no change in the dosage of antipsychotic medication for at least one month prior to the assessment.

The control group (CG) consisted of 19 Hungarian-speaking healthy individuals (eight male and eleven female), recruited from the general community. They had no record of psychiatric (personal or family) and neurological morbidity, presence of dependence on psychoactive substances (excluding caffeine and tobacco). Age, ethnic origin, educational status, and general intelligence were matched to the characteristics of the patients group (Table 1.). All participants were Hungarian native speakers.

After a complete description of the study to the subjects, the written informed consent was obtained. The investigation was done following institutional guidelines. Ethical perspectives were established in accordance with the latest version of the Declaration of Helsinki. This study design is approved by the Committee on Medical Ethics of the University of Pécs. Neither the patients nor the controls were aware of the study aims or hypotheses.

\subsection{IQ}

Participants with normal range of IQ were selected for this study (schizophrenia group: 95-127, mean=109.00, S.D. \pm 9.35 ; control group: 95-122, mean=113.63, S.D. \pm 6.99 ) to exclude an effect of general cognitive impairment on the investigated issue. As the full scale IQ of patients and controls was calculated by the use of the Hungarian version of Wechsler Adult Intelligence Scale (WAIS) (Wechsler 1986), patients and controls were matched for all subtests of WAIS, such as Information, Comprehension, Digit Span, Arithmetic, Similarities, Digit-Symbol Coding, Picture Arrangement, Block design, Picture Completion, and Object Assembly (Table 1.).

\subsection{Experimental tasks}

We used four experimental conditions (see examples in Appendix): first- and second-order Theory of Mind (ToM) tasks (Doody et al. 1998), conversational implicatures (including quality, quantity, manner, relation, and control implicatures) (Tényi et al. 2002; Varga et al. 2014), verbal jokes, and semantic condition. We presented two tasks (i.e. scenarios) in the ToM condition, five tasks in the verbal jokes condition and five tasks in the semantic condition. 20 tasks were presented in the conversational implicatures condition, summing up to a total of 32 tasks $(2+2 \times 5+4 \times 5=32)$ in our study. The 32 tasks were randomly intermixed in order to present the different tasks in an unpredictable order. The randomised tasks were presented verbally by an investigator in the form of an interview in one session for all participants individually. Each interview was recorded, and the recorded data was scored by two independent investigators (E. Varga and Zs. Schnell). The comprehension of the tasks was scored from zero to two. Zero (0) points were given when the answer was incorrect or when there was no answer. One point was given when the answer was correct after asking the experimenter for some help, in the form of clarifying questions. Two points were given when the answer was correct without any help.

\subsubsection{Theory of Mind tasks}

Participants were presented one first-order ToM task to assess the acknowledgement of a character's belief about a word in a short story. One second-order ToM task was also presented to assess the acknowledgement of what one story character thinks about another character's 
thoughts (scenarios were published by Doody et al. 1998). We also asked 'memory questions' and 'reality questions' to make sure participants understand the scenarios. Two points were given when the answer for the ToM question was correct in each trial. The maximum points the subjects could earn were four in this condition.

\subsubsection{Conversational implicatures}

Based on short stories used in the publication of Tényi et al. (2002) and Varga et al. (2014), the total of 20 tasks were presented to the subjects concerning the recognition of the infringement of the four Gricean maxims (four tasks for each type), namely the maxim of quantity, maxim of quality, maxim of manner, and maxim of relation. As for the control tasks in the conversational implicatures condition, we employed four control implicatures tasks that were intended to trigger the literal meaning of the utterance of the speaker. These control tasks consisted of simple dialogues, which did not include any incongruities, and their interpretation did not require ToM skills. After each task the first question concerned the identification of the linguistic incongruity of the answers (called the linguistic part of the implicatures: e.g. "Is this a strange utterance? Why is it strange to say something like this?"). In the case of the implicatures of the quantity maxims the answers in the trial either did not include enough information or included too much information. In the implicatures of quality maxim the answer was not true or the speaker failed to give adequate information. In the implicatures of manner the answer was either not polite, or it was ambiguous, or obscure. Finally, in the implicatures of the maxim of relations the answer was not relevant to the subject at hand. Finally, in the control implicatures the answer always complied with the guidelines set by the Gricean maxims. In the second question the subjects were asked about the understanding of the intended meaning of the speaker's answer (called the ToM part of the implicatures: e.g. "What did the speaker really mean by the utterance?"). To examine each of the implicatures in detail, we scored the linguistic part of the implicatures, designated as L-implicatures (L-relation, L-manner, L-quality, L-quantity) and the ToM part of the implicatures, designated as ToM-implicatures (ToM-relation, ToM-manner, ToM-quality, ToM-quantity) separately. Altogether, the maximum of points the subjects could earn was 40 in this condition (20 points in the linguistic part and 20 points in the ToM part).

\subsubsection{Verbal jokes}

The humour condition consisted of five contextual jokes (Schnell 2012), which were based on story-form jokes ending with a punch line. We primarily asked the participants what they think of the situations (we did not tell them the tasks were jokes). Following their answer we also asked if the situations were funny. If their answer was 'yes', we also asked why they found it funny. Thus, we primarily measured the cognitive aspect of humour comprehension. The maximum of points the subjects could reach was 10 in the humour condition.

\subsubsection{Semantics}

The semantic tasks were used to test schizophrenic patients' semantic competence (that is, their abilities in literal interpretation) with short scenarios based on physical causality of non-living entities, containing no incongruities, and no implicatures. After each task, the subjects were asked questions investigating the comprehension of the target sentences. The maximum of points the subjects could reach were 10 in the semantic tasks (Varga et al. 2014). 


\subsection{Statistical analysis}

The Statistical Package for the Social Science (spss; SPSS Inc., Chicago, IL, USA [Nie 1975]) version 20 for Windows was used for statistical analysis. In the statistical analysis, $\mathrm{P}<.05$ was considered significant. The distribution of data was checked with the Kolmogorov-Smirnov goodness of fit. We used independent sample t-test in the case of parametric data (subtests of WAIS, IQ, and age). As distributions did not prove to be normal, Kruskall-Wallis one-way analysis of variance (ANOVA) by ranks was performed to compare group medians across the experimental conditions. In the schizophrenic group Spearman's rank correlation coefficients $(\rho)$ were calculated to assess the relation between non-literal language tasks scores, and semantic tasks scores, WAIS scores (IQ), as well as PANSS scores.

\section{Results}

In this present investigation the same results are published in the case of demographic and clinical characteristics (3.1), Gricean implicatures tasks, control implicatures tasks, and semantic tasks (3.2) as in our previous study (Varga et al. 2014).

\subsection{Demographic and clinical characteristics}

Demographic data, WAIS scores, and PANSS scores are summarised in Table 1.

There was no significant difference in age $(\mathrm{t}=1.0, \mathrm{p}=0.324$, n.s. $=$ not significant $)$, years of education ( $\mathrm{t}=-1.48, \mathrm{p}=0.146$, n.s.), IQ ( $\mathrm{t}=1.74, \mathrm{p}=0.09$, n.s.), and all of the subtests of WAIS (Information: $\mathrm{t}=0.497, \mathrm{p}=0.399$, n.s.; Comprehension: $\mathrm{t}=0.47, \mathrm{p}=0.772$, n.s.; Digit Span: $\mathrm{t}=0.396$, $\mathrm{p}=0.694$, n.s.; Arithmetic: $\mathrm{t}=1.015, \mathrm{p}=0.318$, n.s.; Similarities: $\mathrm{t}=0.945, \mathrm{p}=0.352$, n.s.; DigitSymbol Coding: $\mathrm{t}=1.82, \mathrm{p}=0.078$, n.s.; Picture Arrangement: $\mathrm{t}=0.661, \mathrm{p}=0.514$, n.s.; Block design: $\mathrm{t}=1.383, \mathrm{p}=0.176$, n.s.; Picture Completion: $\mathrm{t}=0.982$, $\mathrm{p}=0.333$, n.s.; and Object Assembly: $\mathrm{t}=1.184, \mathrm{p}=0.245$, n.s.). 
Table 1. Demographic data and clinical variables on individuals with schizophrenia and healthy control participants. (Table 1. was first published in Varga et al. 2014.)

\begin{tabular}{|c|c|c|c|c|c|}
\hline & \multicolumn{2}{|c|}{ Healthy control $(n=19)$} & \multicolumn{2}{|c|}{ Schizophrenia $(n=19)$} & \multirow[b]{2}{*}{ p-Value } \\
\hline & Percentage & Mean \pm SD & Percentage & Mean \pm SD & \\
\hline $\begin{array}{c}\text { Gender } \\
\text { (\%female) }\end{array}$ & 57.89 & & 47.36 & & $0.334^{\mathrm{a}, \mathrm{c}}$ \\
\hline Age & & $34.89 \pm 10.13$ & & $38.15 \pm 9.99$ & $0.324^{\mathrm{b}, \mathrm{c}}$ \\
\hline $\begin{array}{l}\text { Education } \\
\text { (years) }\end{array}$ & & $15.05 \pm 2.72$ & & $13.58 \pm 2.19$ & $0.058^{b, c}$ \\
\hline Full scale IQ ${ }^{\mathrm{d}}$ & & $113.63 \pm 6.99$ & & $109.00 \pm 9.35$ & $0.090^{\mathrm{b}, \mathrm{c}}$ \\
\hline VQ & & $109.89 \pm 7.29$ & & $108.21 \pm 8.3$ & $0.288^{b, c}$ \\
\hline PQ & & $116.47 \pm 9.92$ & & $109.58 \pm 12.52$ & $0.069^{b, c}$ \\
\hline Information & & $113.76 \pm 11.11$ & & $117.05 \pm 11.37$ & $0.399^{b, c}$ \\
\hline Comprehension & & $106.11 \pm 11.34$ & & $105.05 \pm 9.73$ & $0.772^{b, c}$ \\
\hline Digit Spam & & $103.70 \pm 10.95$ & & $102.11 \pm 12.36$ & $0.694^{b, c}$ \\
\hline Arithmetic & & $96.70 \pm 10.95$ & & $92.23 \pm 14.00$ & $0.318^{b, c}$ \\
\hline Similarities & & $116.23 \pm 6.79$ & & $113.58 \pm 9.33$ & $0.352^{b, c}$ \\
\hline $\begin{array}{c}\text { Digit-Symbol } \\
\text { Coding }\end{array}$ & & $124.23 \pm 13.44$ & & $113.88 \pm 19.21$ & $0.078^{b, c}$ \\
\hline $\begin{array}{c}\text { Picture } \\
\text { Arrangement }\end{array}$ & & $101.58 \pm 14.29$ & & $98.58 \pm 12.09$ & $0.514^{\mathrm{b}, \mathrm{c}}$ \\
\hline Block design & & $122.00 \pm 11.60$ & & $116.11 \pm 13.15$ & $0.176^{\mathrm{b}, \mathrm{c}}$ \\
\hline $\begin{array}{c}\text { Picture } \\
\text { Completion }\end{array}$ & & $108.94 \pm 12.68$ & & $104.29 \pm 14.82$ & $0.333^{b, c}$ \\
\hline $\begin{array}{c}\text { Object } \\
\text { Assembly }\end{array}$ & & $107.29 \pm 10.13$ & & $103.05 \pm 10.72$ & $0.245^{\mathrm{b}, \mathrm{c}}$ \\
\hline $\begin{array}{l}\text { PANSS total } \\
\text { score }\end{array}$ & & & & $68.05 \pm 11.16$ & \\
\hline $\begin{array}{c}\text { PANSS positive } \\
\text { scale }\end{array}$ & & & & $14.63 \pm 3.58$ & \\
\hline $\begin{array}{c}\text { PANSS negative } \\
\text { scale }\end{array}$ & & & & $18.74 \pm 4.85$ & \\
\hline $\begin{array}{l}\text { PANSS general } \\
\text { psychopathology } \\
\text { scale }\end{array}$ & & & & $35.74 \pm 6.41$ & \\
\hline $\begin{array}{c}\text { Age at onset } \\
(\text { years })\end{array}$ & & & & $25.83 \pm 5.18$ & \\
\hline $\begin{array}{c}\text { Duration of } \\
\text { illness (years) }\end{array}$ & & & & $13 \pm 9.10$ & \\
\hline
\end{tabular}

${ }^{a}$ Chi-squared test was used for comparing gender population. 
${ }^{\mathrm{b}}$ Independent sample t-test was used to compare group means.

${ }^{\mathrm{c}}$ Statistically significant differences, two-tailed $\mathrm{p}<0.05$, uncorrected.

$\mathrm{d}$ IQ, the general IQ obtained from the Wechsler Adult Intelligence Scale.

e Age at onset was defined as the presentation of psychotic symptoms in the context of functional decline.

\subsection{Task performance}

Schizophrenic patients performed significantly less accurately than control subjects in the second-order ToM task $(\mathrm{p}=0.013)$, in the verbal jokes tasks $(\mathrm{p}=0.02)$, in all of the ToMimplicatures tasks $(\mathrm{p}<0.001$; ToM relation: $\mathrm{p}=0.02)$, and in all of the L-implicatures tasks $(\mathrm{p}=0.004)$, except the L-quality tasks (see below).

However, no significant differences between the groups were observed in the first-order ToM task ( $\mathrm{p}=0.123$, n.s.) and in the L-quality tasks $(\mathrm{p}=0.052$, n.s.). As expected, there were no significant differences found between the two examined groups in the control implicature tasks $(\mathrm{p}=0.483$, n.s.) and in the semantic tasks $(\mathrm{p}=0.149$, n.s.). (Response accuracy in tasks is summarised in Table 2.) 
Table 2. Response accuracy in experimental tasks.

\begin{tabular}{|c|c|c|c|c|c|}
\hline & \multicolumn{2}{|c|}{ Healthy control $(n=19)$} & \multicolumn{2}{|c|}{ Schizophrenia $(n=19)$} & \multirow[t]{2}{*}{ p-Value ${ }^{a, b}$} \\
\hline & Mean & S.D. & Mean & S.D. & \\
\hline $\begin{array}{c}\text { First-order } \\
\text { ToM }\end{array}$ & 5.58 & 0.77 & 5.32 & 1.00 & 0.123 \\
\hline $\begin{array}{c}\text { Second-order } \\
\text { ToM }\end{array}$ & 3.42 & 0.69 & 2.26 & 1.52 & 0.013 \\
\hline Verbal jokes & 9.79 & 0.63 & 9.11 & 1.97 & 0.02 \\
\hline $\begin{array}{c}\text { ToM- } \\
\text { implicatures }\end{array}$ & 29.42 & 2.65 & 20.11 & 6.13 & $<0.001$ \\
\hline $\begin{array}{c}\text { ToM- } \\
\text { relation }\end{array}$ & 7.53 & 1.02 & 6.21 & 1.90 & 0.021 \\
\hline ToM-manner & 7.47 & 1.02 & 5.00 & 2.11 & $<0.001$ \\
\hline $\begin{array}{c}\text { ToM- } \\
\text { quality }\end{array}$ & 7.00 & 1.25 & 4.42 & 1.95 & $<0.001$ \\
\hline $\begin{array}{r}\text { ToM- } \\
\text { quantity }\end{array}$ & 7.42 & 1.17 & 4.47 & 1.90 & $<0.001$ \\
\hline $\begin{array}{c}\text { L- } \\
\text { implicatures }\end{array}$ & 29.00 & 2.65 & 20.05 & 7.21 & $<0.001$ \\
\hline L-relation & 7.68 & 0.82 & 4.68 & 2.31 & $<0.001$ \\
\hline L-manner & 6.37 & 1.67 & 4.00 & 2.56 & 0.004 \\
\hline L-quality & 7.37 & 1.01 & 6.32 & 1.83 & 0.052 \\
\hline L-quantity & 7.58 & 0.77 & 5.05 & 2.34 & $<0.001$ \\
\hline $\begin{array}{c}\text { Control } \\
\text { implicatures }\end{array}$ & 7.42 & 0.96 & 7.00 & 1.63 & 0.483 \\
\hline $\begin{array}{l}\text { Semantic } \\
\text { tasks }\end{array}$ & 9.95 & 0.23 & 9.68 & 0.65 & 0.149 \\
\hline
\end{tabular}

${ }^{a}$ Kruskal-Wallis nonparametric test was used for comparing response accuracy between groups.

${ }^{\mathrm{b}}$ Statistically significant differences, two-tailed $\mathrm{p}<0.05$, uncorrected.

\subsection{Correlations within the patient groups}

Non-parametric correlation analysis (Spearman correlation) was performed in the schizophrenic group in order to find out the possible associations between the response accuracy in verbal humour tasks and WAIS scores (IQ), ToM scores, response accuracy in the Gricean implicatures, as well as PANSS scores.

We found strong significant correlations between the comprehension of verbal humour and IQ ( $\rho=0.612, p=0.007$; VQ: $\rho=0.471, p=0.006$; PQ: $\rho=0.606, p=0.042)$ and also between verbal humour and L-relation $(\rho=0.518, p=0.023)$, L-quality $(\rho=0.619, p=0.005)$ and L-quantity $(\rho=0.681, p=0.001)$.

There were no significant correlations between verbal humour and first- $(\rho=0.037, p=0.879$, n.s.) and second-order ToM tasks $(\rho=0.380, \mathrm{p}=0.108$, n.s.), PANSS scores (PANSS positive: $\rho=0.015, p=0.951$; PANSS negative: $\rho=-0.139, p=0.570$; PANSS general: $\rho=0.200, p=0.413$; 
PANSS total: $\rho=0.055 ; \mathrm{p}=0.823)$, ToM-implicatures $(\rho=0.333, p=0.163)$, and L-manner $(\rho=0.308, p=0.199)$. Interestingly, we found no significant correlations between humour comprehension and the subtests of WAIS (Information: $p=0.732$, n.s.; Comprehension: $p=0.607$, n.s.; Digit Span: $\mathrm{p}=0.403$, n.s.; Arithmetic: $\mathrm{p}=0.679$, n.s.; Similarities: $\mathrm{p}=0.648$, n.s.; DigitSymbol Coding: $\mathrm{p}=0.914$, n.s.; Picture Arrangement: $\mathrm{p}=0.421$, n.s.; Block design: $\mathrm{p}=0.434$, n.s.; Picture Completion: $\mathrm{p}=0.421$, n.s.; Object Assembly: $\mathrm{p}=0.245$, n.s.)

Interestingly, as we made the correlation analysis in the control and in the patients group together (overall 38 subjects), we observed significant correlations between second-order ToM tasks and verbal humour $(\rho=0.459, \mathrm{p}=0.03)$, and also between ToM-implicatures and verbal humour $(\rho=0.482, p=0.045)$.

\section{Discussion}

As far as we know, this is the first study that examined humour competence in a group of schizophrenic patients with good semantic competence and with good neurocognitive skills, which means good intellectual functions in general. As we hypothesised, we found significant impairment in the comprehension of verbal jokes in schizophrenia. Furthermore, the humour impairment of the patients showed significant associations with IQ and with the inability to detect verbal incongruities in the Gricean implicatures, especially in quality, quantity, and relevance (a.k.a. relation implicatures).

We have long known that patients with schizophrenia experience difficulties in humour abilities (Corcoran et al. 1997; Witztun et al. 1999; Marjoram et al. 2005; Polimeni \& Reiss 2006; Tsoi et al. 2008; Polimeni et al. 2010; Ivanova et al. 2014). Some clinicians even suggest that this particular trait of cognitive functioning, namely, 'sense of humour disorder' can be an important diagnostic criterion in schizophrenia (Forabosco 2007; Ivanova et al. 2014). However, humour disorder has several dimensions in this disease. Ivanova et al. (2014) found that patients with schizophrenia prefer humour based on comparison by latent attribute, and they also express higher laughing response to the jokes based on paradox. They concluded that psychiatric patients do have a sense of humour, but it is altered in comparison with healthy subjects.

In harmony with previous studies, in our present investigation we found that the ability to understand humour is significantly related to intellectual skills. Polimeni et al. (2010) used different neurocognitive tests in order to find potential associations underlying humour deficit in schizophrenia. They found that the patients group performed significantly worse than control subjects on tests of working memory and processing speed (WAIS-III Digit Symbol Coding), executive functions (WCST), verbal comprehension, working memory, and social reasoning. Furthermore, significant associations were found between general intellectual functions (measured by NART), social reasoning, and executive functioning. In most of the studies about humour comprehension in schizophrenia the IQ (reflecting general neurocognitive functions) differences between the schizophrenia groups and the control groups were not significant, but still, the IQ score of the patients (and in some cases, also that of the control subjects) was very low.

In this study of ours contrasting general IQ skills and humour abilities, we would like to emphasise that it is very important methodologically to take the intellectual functions of the tested subjects into account in humour research, since understanding humour is strongly linked to general neurocognitive functions. As for the detailed examination of these general neurocognitive functions of the subjects, in the present research we used WAIS, and patients and 
controls were strictly matched for all subtests of WAIS, to exclude an effect of general cognitive impairment on the investigated issue. We found that humour comprehension was significantly associated with IQ scores, VQ (verbal intelligence) scores, and also with PQ (performative intelligence) scores. In the latter case, the association was not strong, but it still remained. However, we found no significant associations between any subtests of WAIS and humour comprehension in the schizophrenia group, so we can claim that in schizophrenia the comprehension of verbal jokes is strongly linked to intellectual functions in general, especially to verbal intellectual functions. Our earlier findings show (Varga et al. 2014) that at least to some extent, good neurocognitive functions can compensate defected non-literal language comprehension, however, in the case of more demanding dimensions like handling complex pragmatic meanings and embedded implicatures, good neurocognitive functions do not suffice. In this present study, we got similar results, that is, despite good neurocognitive skills of the patients group, humour comprehension deficit still manifests itself. All in all, we can conclude that the comprehension of verbal jokes strongly depends on neurocognitive functions, but good neurocognitive skills do not themselves fully account for the humour skills.

Earlier and recent theories (Attardo 1997; Attardo et al. 2002; Coulson 2001; Bergen \& Binsted 2003) point out that the detection and the resolution of the incongruity of humorous utterances can be the central motive of humour comprehension. In line with this, in our study, humour deficit is significantly associated with an inability to detect the incongruities of the utterances in the Gricean implicatures. Similarly, strong associations were found between humour comprehension and the recognition of quality, quantity, and relation infringements in the patients group (for the results of the Gricean implicatures tasks in the schizophrenic group in detail see Varga et al. 2014). However, there was no significant association found between humour competence and the detection of manner implicatures, which result is supposedly due to the type of the jokes we used. It has been recognised in previous pragmatic research that the infringement of the Gricean maxims could function as a source of jokes (Mancher 1980; Attardo 1994; Kotthoff 2006). According to Giora (2002), an 'optimal innovation' of potential meanings is crucial in the resolution of incongruities and therefore in pragmatic meaning construction, which, we believe, is important for our research in that the comprehension of humorous utterances mostly depends on the selection of the optimally relevant meaning among the competing meanings at hand. Therefore, we conclude that the ability to understand verbal jokes is apparently associated with the ability to understand implicatures.

In humour research, one of the most puzzling questions relates to the efficient demonstration of the relationship between humour and ToM. Some researchers have pointed out the importance of good ToM skills in humour comprehension (Uekermann et al. 2006; Winner et al. 1998; Schnell \& Varga 2012). In contrast, Sullivan et al. (1994) found that a group of 5-8-year-old children who do not yet have the ability to understand what one story character thinks about another character's thoughts (second-order ToM) have the ability to distinguish lie from humour. In schizophrenia research Corcoran et al. (1997) and Marjoram et al. (2005) examined patients' ToM ability with visual, i.e. non-verbal jokes as stimuli, but they did not use separate tasks to see the potential associations between the two functions. Basically, they showed that patients with schizophrenia found it more difficult to understand humour involving the understanding other people's intentions than the ones based on physical analogies. 


\section{Implications}

Thus, as far as we know, the present study is the first which examined associations between ToM functions and punch line based humour comprehension in schizophrenia. We found that the patients group performed significantly worse than control subjects in both the humour processing and in the ToM testing conditions. However, as opposed to our hypothesis, the positive association between the two abilities was not significant in the patients group. As we looked for some further associations together in the patients and in the control group with 38 subjects, however, we found the significant association we previously hoped for, between humour comprehension and second-order ToM comprehension skills. As it has been hypothesised previously, the decoding of the non-literal meaning of humorous utterances requires the deciphering of the intentions of the speaker (Martin 2007; Dennett 1991). This is done by changing perspectives, so that we can see the speaker's point and understand the humorous utterance at hand relying on relevance based interpretations. Previous studies on patients with different pathologies (e.g. alcoholism or different brain injuries, Uekermann et al. 2006; Winner et al. 1998) did find significant associations between ToM abilities and humour competence. We conclude that our present findings about no significant associations between these two abilities in the patients group could be a consequence of a compensating strategy based on their higher neurocognitive abilities. We suppose that they rely on their intact general cognitive abilities (i.e. good verbal skills, memory, IQ) to understand the jokes, thus compensating their impaired second-order ToM abilities. On the other hand, in everyday social interaction people joke in a spontaneous, flexible manner. We believe that ToM functions become far more important in this broader frame of reference, since the real value of using humour in social situations lies in the importance of the hidden message of humorous utterances that is being communicated to the conversational partner. The smooth handling of such spontaneous events in social interaction and of interpersonal humour is thus a very complex issue, incorporating cognitive, linguistic, social, and cultural modalities of personal lives.

\section{Conclusion}

In this study our findings confirmed previous studies' findings in that patients with schizophrenia do have an impaired humour comprehension. Moreover, it was found that humour deficit in schizophrenia is not obviously the result of specific neurocognitive deficits, rather it is the corollary of the inability to understand verbal incongruities in interpersonal discourse.

Based on these findings, we suppose that the use of neurocognitive problem-solving skills in order to understand humour is necessary, but good neurocognitive skills are not sufficient for successful handling of humour. Thus, we argue for the existence of different problem-solving skills, which are distinguished from neurocognitive problem-solving skills and operate on different levels. Since we detected impairments in the recognition of the linguistic incongruities of the Gricean implicatures, which significantly correlated with humour comprehension, we called these skills pragmatic problem-solving skills. We rely on these target social-cognitive strategies when deciphering the intended meaning of the utterance at hand, and in a multi-level simultaneous meaning-construction typical of everyday social interaction. We believe that the inability to use such pragmatic problem-solving skills leads to impaired humour comprehension in schizophrenia. 
A good sense of humour can enrich social relationships, and enhance psychological wellbeing. Thus, humour is important in social functioning and can facilitate social relations. It is also an important source of pleasure in human life (Martin 2007; Tsoi et al. 2008; Polimeni et al. 2010). Furthermore, the power of humour has a positive effect on different physical, psychological, and psychopathological states, because it can blunt the power of utterances (e.g. insults or opinions). Witztum et al. (1999) used a humorous therapeutic approach in the treatment of chronic schizophrenia and found a significant reduction in the BPRS value as a result of humour therapy. Furthermore, amusing representations of affective external stimuli were incorporated into the patients' cognition, and these were retained long after the termination of the project.

Therefore, we argue for the importance of the mapping of the cognitive background of humour comprehension in detail, in order to find potential cognitive treatment targets in schizophrenia, such as neurocognitive functions, and pragmatic abilities, which in turn will possibly facilitate patients' humour comprehension: the latter is, we believe, one of the most important features of human social cognition. It is also of key importance to achieve a full "cognitive understanding" of schizophrenia, especially when it comes to humour, so that humour comprehension and expression could be a potential treatment target in order to enhance the quality of life, to be able to lead a more fulfilling life with schizophrenia.

\section{Limitations of the study}

The interpretation of our data is limited by the small number of subjects, by the small number of the experimental tasks, and by the heterogeneity of the antipsychotic treatment. At the present stage of our study we have not examined the effect of the received antipsychotic medications on the investigated skills in the patients group. All of the patients in our study received antipsychotic medication, and the high diversity of the applied medication made it difficult to examine it statistically.

We also did not use any questionnaires or tests to measure social functioning in schizophrenic patients. Since these patients are often socially isolated, and humour comprehension strongly relies on social experiences and participation, it would be highly important to take into account the social functioning skills of patients in further studies.

In the present study we basically examined the comprehension of verbal humour, using classical jokes ending in punch lines. We have to point out, however, that it is very important to keep in mind that the handling of humour is impaired in schizophrenia in two dimensions: not only in perception (as we examined through linguistic tasks), but also in expression. At the present stage of our examination we cannot determine to what extent patients' limitations were due to atypical patterns in perception (humour processing and joke comprehension), in expression (sense of humour in terms of producing jokes or funny remarks), or both.

In sum, our findings have to be confirmed in future studies with a higher number of participants with a higher number of experimental tasks and with more homogeneously medicated schizophrenic patients in order to be able to draw a more generalised conclusion on the investigated issue. 


\section{Disclosure statement}

We are not aware of any actual or potential conflicts of interest regarding this work.

\section{Acknowledgements}

This research was supported by the National Brain Research Program Grant No. NAP KTIA NAP-A-II/12.

E. Varga was supported by TÁMOP-4.1.1.C-13/1/KONV-2014-0001.

Zs. Schnell was supported by TÁMOP 4.2.4. A/2-11-1-2012-0001 National Excellence Program - Elaborating and operating an inland student and researcher personal support system convergence program. The project was subsidised by the European Union and co-financed by the European Social Fund.

Zs. Schnell was supported by SROP-4.2.2.C-11/1/KONV-2012-0005 (Well-Being in the Information Society project) in the framework of the Theoretical, Computational and Cognitive Linguistics Research Group (ReALIS) at the University of Pécs, Department of Linguistics.

\section{Appendix}

1. Theory of Mind tests (based on Doody et al. 1998)

Please respond to the following questions:

First-order ToM test:

Kate and Peter are playing in a room. Kate puts her ball into a basket, and leaves the room. At this point, Peter enters the room, takes the ball from the basket and places it into a box.

First-order Theory of Mind (ToM) question:

Where will Kate look for the ball when she goes back to the room?

Memory question: Where did Kate put the ball?

Reality question: Where is the ball now?

Second-order ToM test:

Sarah and John are waiting at a train station. Sarah would like to travel home, but the train does not stop at the town she aims to go to, only at a small settlement nearby, from where she needs to walk home. Sarah decides to buy a newspaper before she buys her ticket. While she is away, some changes are introduced in the timetable, and it turns out, that her train actually stops at the town. John learns about this change, and he decides to find Sarah as soon as possible. She, however, also meets a ticket inspector, who brings the novel changes to her attention. John eventually finds Sarah, but by then, she has already bought the tickets.

Second-order ToM question: To what destination does John think Sarah bought the ticket?

Memory question: Where did Sarah go to while they were waiting at the station?

Reality question: To what destination did Sarah buy the tickets? 
2. Tasks on the recognition of the infringement of conversational maxims

Tell us your opinion about the responses you hear!

Is there anything strange for you in the responses?

What does the responding person really think?

MAXIM OF RELEVANCE: A professor is asked if he is satisfied with his teaching assistant. - She is a woman! - replies the professor.

MAXIM OF MANNER: One afternoon Daisy turns to Ray and says: - The weather is so lovely and sunny today, let's go out and play football!

Ray replies: - I will sure not go with you; you are so clumsy, you fall over your own legs!

MAXIM OF QUANTITY: In the evening Judy asks Zack what he would like to have for dinner.

- I'd like something to eat - says Zack.

MAXIM OF QUALITY: Betty and Greg are talking about their supper the night before. Betty asks: - What did you order in the restaurant? - I ordered two whole pigs - says Greg.

3. Humour tasks (Schnell 2012)

What do you think of the following situation?

(Is this funny? If so, why?)

a) Some friends are fishing.

First they pull out a teapot, then a pan, and finally a shoe from the lake. One cries out: - Hey buddies, let's get out of here, I think someone lives here!

b) Ben is boasting to his mum: - Hey mum, I caught five flies, two males and three females.

Mom: - How do you know which one was a male and a female?

- Two were sitting on the table, and three in front of the mirror.

c) - Where did you spend your summer? - I spent half in the mountains, and half in my plaster cast...

4. Control tasks

Please respond to the following questions:

a) There is an apple tree and a plum tree in the garden. A strong wind comes and it blows so hard, all the fruits end up on the ground, none stay on the trees.

Question: Do the fruits stay on the trees after the storm?

b) A fox and a wolf are standing on the frozen lake. The fox goes to an area where the ice is very thin, and so it breaks, and the fox sinks into the water. 
Does the thin ice break under the fox causing it to sink?

c) Alex invites Bob over to his house for a chat. Before Bob's visit Alex paints the entrance door. When Bob arrives, he nearly faints due to inhaling the fresh paint. Bob says: - Your house does smell good!

Does Bob think that Alex's house does not smell good?

\section{References}

Abu-Akel, A. (1999). 'Impaired theory of mind in schizophrenia'. Pragmatics and Cognition 7 (2), pp. 247-282.

Attardo, S. (1994). 'Linguistic theories of humour'. Studies in Language 22 (1), pp. 205-212.

Attardo, S. (1997). 'Competition and cooperation: Beyond Gricean pragmatics'. Pragmatics and Cognition 5 (1), pp. 21-50.

Attardo, S., Hempelmann, C. F. \& Di Maio, S. (2002). 'Script oppositions and logical mechanisms: modeling incongruities and their resolutions'. HUMOR: International Journal of Humor Research 15 (1), pp. 3-46.

Bergen, B. \& Binsted, K. (2003). 'The cognitive linguistics of scalar humor'. Language, culture, and mind, pp. 79-92.

Bora, E., Gökçen, S., Kayahan, B. \& Veznedaroglu, B. (2008). 'Deficits of social-cognitive and social-perceptual aspects of theory of mind in remitted patients with schizophrenia: effect of residual symptoms'. The Journal of nervous and mental disease 196 (2), pp. 95-99.

Bora, E., Yucel, M. \& Pantelis, C. (2009). 'Theory of mind impairment in schizophrenia: metaanalysis'. Schizophrenia Research 109 (1-3), pp. 1-9.

Brothers, L. (1990). 'The neural basis of primate social communication'. Motivation and Emotion 14 (2), pp. 81-91.

Brüne, M. \& Bodenstein, L. (2005). 'Proverb comprehension reconsidered - 'theory of mind' and the pragmatic use of language in schizophrenia'. Schizophrenia research 75 (2-3), pp. 233 239.

Champagne-Lavau, M. \& Stip, E. (2010). 'Pragmatic and executive dysfunction in schizophrenia'. Journal of Neurolinguistics 23 (3), pp. 285-296.

Colle, L., Angeleri, R., Vallana, M., Sacco, K., Bara, B.G. \& Bosco, F.M. (2013). 'Understanding the communicative impairments in schizophrenia: a preliminary study'. Journal in Communication Disorder 46 (3), pp. 294-308.

Coulson, S. (2001). Semantic leaps: Frame-shifting and conceptual blending in meaning construction. Cambridge: Cambridge University Press.

Corcoran, R. \& Frith, C.D. (1996). 'Conversational conduct and the symptoms of schizophrenia'. Cognitive Neuropsychiatry 1 (4), pp. 305-318.

Corcoran, R., Cahill, C. \& Frith, C.D. (1997). 'Appreciation of visual jokes in people with schizophrenia: a study of 'mentalizing' ability'. Schizophrenia Research 24 (3), pp. 319-327.

Dennett, D. C. (1989). The Intentional Stance. A Bradford Book.

Dennett, D. C. (1991). Consciousness Explained. Boston, MA: Little, Brown and Company.

Doody, G.A., Götz, M., Johnstone, E.C., Frith, C.D. \& Owens, D.G. (1998). 'Theory of mind and psychoses'. Psychological Medicine 28 (2), pp. 397-405. 
Drury, V. M., Robinson, E. J. \& Birchwood, M. (1998). “"Theory of mind” skills during an acute episode of psychosis and following recovery'. Psychological Medicine 28 (5), pp. 11011112.

Endicott, J. \& Spitzer, R. L. (1978). 'A diagnostic interview: the schedule for affective disorders and schizophrenia'. Archives of general psychiatry, 35 (7), pp. 837-844.

Forabosco, G. (2007). 'The ill side of humor: Pathological conditions and sense of humor', in Ruch, W. (eds.), Sense of humor: explorations of personality characteristic, New York: Mouton de Gruyter, pp. 271-292.

Frith, C. D. \& Frith, U. (1999). 'Interacting minds - a biological basis'. Science 286 (5445), pp. 1692-1695.

Gardner, H., Ling, P. K., Flamm, L. \& Silverman, J. (1975). 'Comprehension and appreciation of humorous material following brain damage'. Brain 98 (3), pp. 399-412.

Gavilán, J. M. \& García-Albea, J. E. (2011). 'Theory of mind and language comprehension in schizophrenia: Poor mind-reading effects figurative language comprehension beyond intelligence deficits'. Journal of Neurolinguistics 24, pp. 54-69.

Giora, R. (2002). 'Literal vs. figurative language: Different or equal?'. Journal of Pragmatics 34 (4), pp. 487-506.

Grice, H.P. (1968). 'Utterer's meaning, sentence-meaning and world meaning'. Foundations of Language 4 (3), pp. 225-242.

Grice, H.P. (1975). 'Logic and conversation', in Cole, R. \& Morgan, J. (eds.), Syntax and semantics: Speech Acts, New York: Academic Press.

Herold, R., Tényi, T., Lénárd, K. \& Trixler, M. (2002). 'Theory of mind deficit in people with schizophrenia during remission'. Psychological Medicine 32 (6), pp. 1125-1129.

Inoue, Y., Yamada, K., Hirano, M., Shinohara, M., Tamaoki, T., Iguchi, H., Tonooka, Y. \& Kanba, S. (2006). 'Impairment of theory of mind in patients in remission following first episode of schizophrenia'. European Archives of Psychiatry and Clinical Neuroscience 256 (5), pp. 326-328.

Ivanova, A. M., Enikolopov, S. N. \& Mitina, O. V. (2014). 'Sense of humor disorders in patients with schizophrenia and affective disorder'. Psychology of Russia 7 (1), pp. 146-157.

Kay, S. R. \& Opler, L. A. (1987). 'The positive-negative dimension in schizophrenia: its validity and significance'. Psychiatric developments, 5 (2), pp. 79-103.

Kotthoff, H. (2006). 'Gender and humour: The state of the art'. Journal of Pragmatics 38 (1), pp. 4-25.

Langdon, R., Davies, M. \& Coltheart, M. (2002a). 'Understanding minds and understanding communicated meanings in schizophrenia'. Mind \& Language 17 (1-2), pp. 68-104.

Langdon, R., Coltheart, M., Ward, P. B. \& Catts, S. V. (2002b). 'Disturbed communication in schizophrenia: the role of poor pragmatics and poor mind reading'. Psychological Medicine 32 (7), pp. 1273-1284.

Mancher, M. (1980). 'How to play games with words: Speech-act jokes'. Journal of Literary Semantics 9 (1), pp. 20-29.

Marjoram, D., Tansley, H., Miller, P., MacIntyre, D., Owens, D. G., Johnstone, E. C. \& Lawrie, S. (2005). 'A theory of mind investigation into the appreciation of visual jokes in schizophrenia'. BMC Psychiatry 5 (12).

Martin, R. A. (2007). The Psychology of Humor: An integrative approach. Burlington, MA: Elsevier Academic Press. 
Mazza, M., Michele, V. D., Pollice, R., Casacchia, M. \& Roncone, R. (2008). 'Pragmatic language and theory of mind deficits in people with schizophrenia and their relatives'. Psychopathology 41 (4), pp. 254-263.

Mo, S., Su, Y., Chan, R. C. K. \& Liu, J. (2008). 'Comprehension of metaphor and irony in schizophrenia during remission: The role of theory of mind and IQ'. Psychiatry Research 157 (1-3), pp. 21-29.

Nemesi, A. L. (2009). Alakzatok kérdése a pragmatikában. Budapest: Loisir Publishing Group.

Nie, N. H. (1975). SPSS: statistical package for the social sciences. McGraw-Hill Companies.

Pinkham, A. E., Penn, D. L., Green, M. F. \& Healey, K. P. (2014). 'The social cognition Psychometric Evaluation study: results of the expert survey and RAND panel'. Schizophrenia Bulletin 40 (4), pp. 813-823.

Polimeni, J. \& Reiss, J. P. (2006). 'Humor perception deficit in schizophrenia'. Psychiatry Research 141 (2), pp. 347-366.

Polimeni, J. O., Campbell, D. W., Gill, D., Sawatzky, B. L. \& Reiss, J.P. (2010). 'Diminished humour perception in schizophrenia: relationship to social and cognitive functioning'. Journal of Psychiatry Research 44 (7), pp. 434-440.

Schnell, Zs. (2012). 'The development of humour competence in Hungarian children - a cognitive approach', in T. Litovkina, A., Szőllősy, J., Medgyes, P., Chłopicki, W. (eds.), Hungarian Humour. Humor and Culture 3, Cracow: Tertium Society for the Promotion of Language Studies, pp. 235-251.

Schnell, Zs. \& Varga, E. (2012). 'Humour, irony and social cognition', in T. Litovkina, A., Szőllősy, J., Medgyes, P., Chłopicki, W. (eds.), Hungarian Humour. Humor and Culture 3, Cracow: Tertium Society for the Promotion of Language Studies, pp. 253-270.

Sperber, D. \& Wilson, D. (1986). Relevance: Communication and cognition. Oxford: Blackwell.

Sperber, D. (2000). Metarepresentations: A Multidisciplinary Perspective. Oxford: Oxford University Press.

Sullivan, K., Zaitchik, D. \& Tager-Flusberg, H. (1994). 'Preschoolers can attribute second-order beliefs'. Developmental Psychology, 30 (3), pp. 395-402.

Suls, J. M. (2007). 'Cognitive processes in humour appreciation', in Baldwin, E. (eds.), Humor perception: The contribution of cognitive factors. Georgia State University.

Tényi, T., Herold, R., Szili, I. M. \& Trixler, M. (2002). 'Schizophrenics show a failure in the decoding of violations of conversational implicatures'. Psychopathology 35 (1), pp. 25-27.

Tsoi, D. T., Lee, K. H., Gee, K. A., Holden, K. L., Parks, R. W. \& Woodruff, P.W. (2008). 'Humour experience in schizophrenia: relationship with executive dysfunction and psychosocial impairment'. Psychological Medicine 38 (6), pp. 801-810.

Uekermann, J., Channon, S., Winkel, K., Schlebusch, P. \& Daum, I. (2006). 'Theory of mind, humour processing and executive functioning in alcoholism'. Addiction 102, pp. 232-240.

Varga, E., Simon, M., Tényi, T., Schnell, Zs., Hajnal, A., Orsi, G., Dóczi, T., Komoly, S., Janszky, J., Füredi, R., Hamvas, E., Fekete, S. \& Herold, R. (2013). 'Irony comprehension and context processing in schizophrenia during remission - A functional MRI study'. Brain and Language 126 (3), 231-242.

Varga, E., Schnell, Zs., Tényi, T., Németh, N., Simon, M., Hajnal, A., Horváth, R., Hamvas, E., Járai, R., Fekete \& S. Herold, R. (2014). 'Compensatory effect of general cognitive skills on non-literal language processing in schizophrenia'. Journal of Neurolinguistics 29, 1-16.

Veatch, T.C. (1998). 'A theory of humor'. HUMOR: International Journal of Humor Research 11, pp. 161-215. 
Wechsler, D. (2007). The Measurement of Adult Intelligence. Kessinger Pub Co.

Winner, E., Brownell, H., Happé, F., Blum, A. \& Pincus, D. (1998): 'Distinguishing lies from jokes: Theory of mind deficit and discourse interpretation in right hemisphere brain damage patients'. Brain and Language 62, pp. 89-106.

Witztum, E., Briskin S. \& Lerner, V. (1999). 'The use of humor with chronic schizophrenic patients'. Journal of Contemporary Psychoterapy 29 (3), pp. 223-234.

Woodruff, G. \& Premack, D. (1978). 'Does the Chimpanzee Have a Theory of Mind'. Behavioral and Brain Sciences 4, pp. 515-526. 